\title{
Targeted Awareness: Promoting Niche Resources Using Confirmation Emails
}

\author{
Brian Rennick \\ Brigham Young University - Provo, brian_rennick@byu.edu \\ Leticia Camacho \\ Brigham Young University - Provo, leticia_camacho@byu.edu \\ Andy Spackman \\ Brigham Young University - Provo, andy_spackman@byu.edu
}

Follow this and additional works at: https://scholarsarchive.byu.edu/facpub

Part of the Library and Information Science Commons

\section{Original Publication Citation}

Rennick, B., Camacho, L. and Spackman, A. (2020), "Targeted awareness: promoting niche resources using confirmation emails", Library Management, Vol. 41 No. 4/5, pp. 183-191. https://doi.org/10.1108/LM-11-2019-0083

\section{BYU ScholarsArchive Citation}

Rennick, Brian; Camacho, Leticia; and Spackman, Andy, "Targeted Awareness: Promoting Niche Resources Using Confirmation Emails" (2020). Faculty Publications. 4196.

https://scholarsarchive.byu.edu/facpub/4196

This Peer-Reviewed Article is brought to you for free and open access by BYU ScholarsArchive. It has been accepted for inclusion in Faculty Publications by an authorized administrator of BYU ScholarsArchive. For more information, please contact ellen_amatangelo@byu.edu. 


\title{
Targeted awareness: Promoting niche resources using confirmation emails
}

\begin{abstract}
Purpose - This paper examines the effectiveness of a targeted email advertising method that informs university students about library resources relevant to their major.

Design/methodology/approach - Over the course of one semester, students with business and communications majors who reserved group study rooms received customized confirmation emails that included targeted advertisements for library databases. These advertisements invited students to click a link that led to a database related to a student's major. Near the end of the semester, students were invited to complete a short survey about the advertisements. Survey questions were designed to discover whether the advertisements were seen and to measure database relevancy. The survey also gathered participant perceptions about the value of this targeted awareness advertising approach.
\end{abstract}

Findings - Overall, the technique of appending database advertisements to reservation emails proved ineffective; very few students recalled seeing the advertisements or clicking the links. On the positive side, the study showed that very few of the survey respondents disapproved of receiving advertisements. Another positive result was that a majority indicated the selected library databases were relevant to their needs. Respondents also offered suggestions for improving this marketing technique.

Originality/value - This research introduces a novel, unobtrusive approach to advertising library resources to a targeted audience. The results can be used by library administrators as a starting point for experimenting with similar (yet improved) methods of sharing information about relevant library resources with specific user populations.

Keywords - marketing, targeted advertising, databases

Paper type - Research paper

\section{Introduction}

This research tested the effectiveness of a targeted awareness advertising campaign that informs university students about niche electronic resources relevant to their major.

Undergraduates who reserve group study rooms in the library are routinely sent a confirmation email. This study involved embedding a relevant advertisement in each reservation email and tracking whether the link in the advertisement was clicked. A subset of business and communications undergraduate students with accounting, advertising, and public relations majors, along with pre-management and pre-communications students, served as the study 
population. The study was conducted for one semester. Near the end of the semester, a brief survey was sent to each student who received an advertisement.

One of the Library's strategic initiatives is to improve the discoverability of scholarly resources. In 2019, an Ithaka S+R library survey was administered to students and faculty, there were thirty-two comments from students and faculty that indicated a need for more information about library resources. The comments were an indication that students are often unaware of the information resources that may benefit them the most. One student comment stated, "The library is great, but a lot of students (my peers) don't know about the resources available." This study evaluated a newly proposed method of advertising library resources to students: targeted awareness.

Current advertising of resources includes library instruction classes, the library's website, social media posts, and video displays. However, these methods typically broadcast messages to a wide audience, thus focusing on promoting resources of general interest. Personal outreach by liaison librarians has been the most effective method of sharing information about niche resources with faculty and students in specific disciplines, but such efforts do not scale efficiently. In an effort to supplement these methods, the library's web development team suggested embedding targeted advertisements in routine email communications sent to students. This approach is called "targeted awareness" because the advertisements target students based on their major in order to raise awareness of discipline-specific resources.

In order to avoid overwhelming students with excessive email, the web development team decided that advertisements should not be sent as standalone messages; instead, advertisements were attached to emails that students already receive during the course of regular library business. For this pilot study, the researchers used confirmation emails that students receive when they reserve a group study room. The targeted awareness process embeds an advertisement in the confirmation email before it is sent to a student. These advertisements were crafted by subject librarians who are knowledgeable about students' fields of study.

\section{Literature review}

Librarians are constantly looking for ways to make patrons aware of available services and resources. New marketing technologies have increased opportunities to deliver this information in innovative and creative ways. These marketing efforts and the methods they employ are reflected in the literature. Millet and Chamberlain (2007) recognized the importance of using "a multitude of approaches" in order to "guide students to the appropriate resources" since students often select free web resources instead of paid content from the library (p. 97). Kennedy (2011) reviewed articles about the marketing of electronic resources by academic libraries and identified several techniques, including during group training, email, flyers, direct mail, newspaper advertising, social media, web page advertising, user guides, and surveys. The most popular technique was group training, and the second most popular was email. 
David and Sagun (2012) reported that an academic library more than doubled the number of electronic database searches in a period of one year after implementing a marketing plan. This campaign consisted of placing printed handouts at reference desks and sending email advertisements to all undergraduate students.

Ellis (2004) described some of the attempts to market electronic resources at an academic library by providing training courses. The study revealed that fewer people attended general training courses than custom presentations about subject-specific databases. During those trainings, students and faculty were invited to sign up for an email service that sends out alerts when new electronic resources become available for a subject area of interest.

Another academic library decided to focus its marketing efforts on students in specific majors because many of the library's electronic resources are primarily relevant to specific subject disciplines. During this study, targeted emails were sent to segments of students instead of mass emails being sent to the entire student population (Dubicki, 2007). The study found that segmentation by academic major is one effective approach for matching electronic resources to students. This segmentation process is best described by Potter (2012). The process involves dividing up the student population into groups with similar interests and "developing different value propositions for each of them" (p. 27). Potter claimed that segmentation to specific targets contributes to a marketing process that appeals to a specific segment (p. 29).

The library where this research was conducted directs many similar marketing efforts, including the use of emails, newsletters, social media, flyers, digital signage, and so forth. In this study we experimented with a new approach by sending different email advertisements about subjectspecific electronic resources to students based on their majors. The advertisements were included in confirmation emails for group study rooms that students already receive. Students who schedule these rooms can be considered existing customers of the library because they are already using a library service (study rooms) and a library tool (the online reservation system). Bodapati (2008) pointed out that add-on selling to existing customers "makes sense if the customer acquisition cost is high relative to the marketing cost required to induce purchases from existing customers" (p. 78). In other words, students who already use the library might be more receptive to trying additional library services or resources than students who do not use the library, so targeting current users provides the best opportunity to test the effectiveness of a new promotional campaign.

Consumers react more positively to customized content and targeted advertising, or advertising perceived to be personalized (see, for example, De Keyzer et al., 2015, and Kalyanaraman \& Sundar, 2006). In contrast to uninvited spam, the library's targeted awareness approach is similar to marketing campaigns that build on existing relationships by using consumers' purchasing histories to recommend additional purchases. According to Chittenden and Rettie (2003), "consumers and customers treat their inbox as a personal domain. As long as companies seek permission to send messages, and do not abuse this privilege, they have the ability to build profile, awareness and, ultimately, a profitable relationship with that person" ( $p$. 205). 
Whang (2007) measured the success of library website banner advertisements using conversion rates, defined as "how many library visitors arrived at the site vs. how many actually did something that was in alignment with the website's goal" (p. 98). In a similar fashion, the [University Library's] conversion rate for the targeted awareness campaign was the number of study room reservation emails sent divided by the number of clicks on the embedded advertisements. By means of a follow-up survey, qualitative measures of success were also obtained.

\section{Research constructs and objectives}

The objective of this study was to determine whether or not a targeted awareness approach shows promise as an effective way for academic libraries to inform university students about relevant electronic library resources. The study was designed to answer two research questions:

1. Is a targeted awareness email advertising campaign an effective technique for increasing awareness and use of electronic library resources by business and communications undergraduates?

2. How do students feel about receiving personalized advertisements for library resources?

\section{Methodology}

Research subjects

The study population was limited to subsets of students majoring in business or communications who reserve library study rooms. Students studying the areas of premanagement, accounting, advertising, public relations, and pre-communications were included. A sample taken from system logs indicates that about 380 students per month from the selected majors reserve study rooms in the library. It was expected that running the study for about three months (one semester) would include approximately 1,140 students $(380 \times 3)$. The majors were selected by the two subject librarians who designed the advertisements.

Subjects who received a survey were given the opportunity to enter a drawing for $\$ 10$. The amount was deemed appropriate since the survey only required a few minutes to complete. Twenty cash awards were granted. Given the maximum estimate of 1,140 participants, the odds for winning were estimated as 1:56 or better depending on the number of students who actually responded to the survey.

The study was exploratory in nature and the sampling method was based on convenience; the sample used in the study is not representative of the university's student population. 


\section{Research methods}

Two subject librarians were part of the initial evaluation of the targeted awareness system. They prepared a pool of three advertisements for each of the three test groups of targeted business and communications undergraduates. Group one was pre-management students, group two was accounting students, and group three was a composite of advertising, public relations, and pre-communications students.

Students did not need to self-report their major to receive a customized advertisement. When they signed in to reserve a study room, their major was retrieved from the university's student account web service. If they fell within one of the selected majors, an advertisement was randomly selected from the appropriate pool and embedded in their reservation confirmation email. For example, an accounting major could have received an advertisement for the Tax Notes database on one day and an advertisement for the ProQuest Accounting and Tax database on another day. The advertisements included an invitation to click a link that led to the featured database.

[Insert Figure 1 here]

When a confirmation email was sent, the student's email address and major were recorded in a system log. If the student clicked on the advertisement's link, a record of the click was stored in another log file on the web server along with information regarding the student's email address, major, and which advertisement was clicked on.

During the actual study period, 816 students in the selected majors reserved study rooms. Near the end of the semester, all of them received an invitation to complete a short online survey about the customized advertisements they received. The survey instrument did not retain names or identifying information, but the responses were correlated with student majors and the types of advertisement they received. Students who completed the survey were given an opportunity to enter a drawing to receive one of twenty $\$ 10$ cash incentives.

The purpose of the survey was to gather data about students' perceptions of targeted awareness. The survey was designed specifically for this study. It contained seven questions plus an opportunity to enter a drawing. The questions were designed to determine if students viewed the targeted advertisements about library resources and whether they found the advertised resources relevant. (See the end of the section for an example of the survey instrument.) Entering contact information for the drawing took place in a separate process in order to avoid associating the person with their survey response.

\section{Data analysis}

Quantitative: 
Data from the survey were used to determine how many participants noticed the advertisements and clicked on them. This was compared to server log records of how often the links had been clicked. Survey questions were also used to see if the databases in the advertisements were relevant to the student, had been used by the student in the past, and were likely to be used in the future.

Qualitative:

Data from the survey were also used to gather participant perceptions about the value of a targeted awareness advertising approach. Comments from participants were coded and categorized to facilitate analysis.

[Insert Figure 2 here]

\section{Results}

Overall response

The survey had a $27 \%$ response rate (223 out of 816 ).

[Insert Table 1 here]

Four of the survey respondents indicated that they did not remember receiving any study room reservation confirmation emails, so they did not continue past the first question of the survey.

Twelve people, just $5 \%$ of respondents, recalled seeing the embedded advertisements. Even fewer recalled clicking on the link to the advertisement. The low engagement rates reported in the survey are confirmed by server logs, which show that only five of the 816 advertisements included in reservation emails received clicks.

[Insert Table 2 here]

Database relevancy and use

Respondents were asked about three databases related to their individual majors. These were the same databases that were promoted in the advertisements. Respondents indicated whether or not each database was relevant to them and whether or not they had used the database before. They also indicated whether or not they were likely to use the database in the future.

[Insert Table 3 here] 


\section{Coded comments}

A high number of responses, 142 out of 223 (64\%), included comments. Written comments were coded to determine how respondents felt about the idea of including advertisements in study room reservation confirmation emails. Some comments were assigned more than one code. About $25 \%$ of the comments were positive and less than $3 \%$ of the comments were negative.

[Insert Table 4 here]

\section{Discussion}

The accounting majors showed far more interest in their targeted databases than the other majors did. For example, $64 \%$ of the 88 accounting majors who responded to the survey felt that the Accounting \& Tax database was relevant, and 55\% planned to use it in the future. By comparison, only $19 \%$ of the 75 communications majors felt that the Ad Age database was relevant to them, and only $23 \%$ had plans for future use.

These results may partly reflect differences in program composition. At [University], accounting majors are all accounting students, while communications majors may be advertising, public relations, or journalism students, and management majors may be entrepreneurship, strategy, or human resources students. As a result, an accounting database has the potential to be relevant to all accounting majors, but an advertising database has the potential to be relevant to only a subset of communications majors. This underscores the fact that librarians may not be able to target their promotional efforts with equal granularity across different student populations.

In addition, unlike the actual advertisements, the survey provided little context when asking whether students thought a database was relevant. While some databases have obviously relevant names, like Accounting \& Tax, others, like IBIS World, do not. This may account for some of the variability in responses to the question about database relevancy.

\section{Conclusion}

The attempt to target students with relevant database advertisements was generally ineffective. Very few recalled seeing or responding to the advertisements, partly because so many respondents ignore or pay little attention to their reservation confirmation emails. Such routine emails may not be effective vehicles for advertising, whether targeted or not. This echoes a finding from Bang and Wojdynski (2016) that although personalized advertisements usually attract and hold attention longer than non-personalized ones, "when people are not strongly engaged and involved in the media consumption process on the web, they tend to 
show habitual and automatic ad avoidance phenomenon for both personalized and nonpersonalized ads" (p. 872).

Despite the overall failure, the study did bring to light some evidence of potential for this approach:

- $63 \%$ of students (140 out of 223 ) indicated that the selected databases are relevant to their needs.

- $25 \%$ of students (36 out of 142 ) made positive comments about the approach; less than $3 \%$ (4 out of 142) disapproved.

- $26 \%$ of students ( 37 out of 142 ) offered suggestions on how to improve the advertising.

Based on these positive results, further efforts to use targeted advertising may be warranted if techniques are modified and tested. For example, the response rate for the survey was $27 \%$, much higher than the $5 \%$ of respondents who noticed the advertisements. This suggests that targeted advertisements in separate emails might receive more attention than advertisements embedded within confirmation emails. However, such an approach should include an option for students to opt-out of additional emails, even though the free-response comments reflect a generally positive reaction to the concept of targeted advertisements. 


\section{References}

Bang, H. and Wojdynski, B.W. (2016), "Tracking users' visual attention and responses to personalized advertising based on task cognitive demand", Computers in Human Behavior, Vol. 55 Part B, pp. 867-76, doi:10.1016/j.chb.2015.10.025.

Bodapati, A.V. (2008), "Recommendation systems with purchase data", Journal of Marketing Research, Vol. 45 No. 1, pp. 77-93.

[University Library] (2019), Ithaka S+R survey report, Internal [University Library] report, Unpublished.

Chittenden, L. and Rettie, R. (2003), "An evaluation of e-mail marketing and factors affecting response", Journal of Targeting, Measurement and Analysis for Marketing, Vol. 11, pp. 203-17.

David, L.T. and Sagun, K.K.A. (2012), "Increasing awareness and use of the library's resources and facilities through relationship marketing strategies", Library Management, Vol. 33 No. 4/5, pp. 292-96, doi: 10.1108/01435121211242326.

De Keyzer, F., Dens, N. and De Pelsmacker, P. (2015), "Is this for me? How consumers respond to personalized advertising on social network sites", Journal of Interactive Advertising, Vol. 15 No. 2, pp. 124-34, doi: 10.1080/15252019.2015.1082450.

Dubicki, E. (2007), "Basic marketing and promotion concepts", The Serials Librarian, Vol. 53 No. 3, pp. 5-15, doi: 10.1300/J123v53n03_02.

Ellis, R. (2004), "Marketing of electronic resources: Projects and experiences", Serials, Vol. 17 No. 1, pp. 57-59.

Kalyanaraman, S. and Sundar, S.S. (2006), "The psychological appeal of personalized content in web portals: Does customization affect attitudes and behavior?", Journal of Communication, Vol. 56 No. 1, pp. 110-32, doi:10.1111/j.1460-2466.2006.00006.x.

Kennedy, M. (2011), "What are we really doing to market electronic resources?", Library Management, Vol. 32 No. 3, pp. 144-58, doi: 10.1108/01435121111112862.

Millet, M.S. and Chamberlain, C. (2007), "Word-of-mouth marketing using peer tutors", The Serials Librarian, Vol. 53 No. 3, pp. 95-105, doi: 10.1300/J123v53n03_07.

Potter, N. (2012), The Library Marketing Toolkit, Facet Publishing, London, England.

Whang, M. (2007), "Measuring the success of the academic library website using banner advertisements and web conversion rates: A case study", Journal of Web Librarianship, Vol. 1 No. 1, pp. 93-108, doi: 10.1300/J502v01n01_07. 
Figure 1. Advertisement sent by email.

A library database for you:

\section{(?) eMarketer PRO}

Want data on how people use the internet, mobile, and social media? Use eMarketer for statistics and analysis on consumer behavior, advertising, and media consumption. Graphics download easily for papers and presentations. eMarketer can be found on theAdvertising or PR Research Guides. Try it now! 
Figure 2. Respondent survey used to gather qualitative data.

Survey instrument for pre-management students

1. Do you remember receiving one or more emails from the library confirming your study room reservations during this semester?

() Yes

() No [ go to the end of the survey ]

2. Each of the study room confirmation emails sent to you this semester contained an advertisement for a library database. Please answer the following questions by checking the appropriate boxes.

\begin{tabular}{|l|l|l|l|l|}
\cline { 2 - 5 } \multicolumn{1}{c|}{} & IBIS World & $\begin{array}{c}\text { Euromonitor } \\
\text { Passport }\end{array}$ & $\begin{array}{c}\text { Mergent } \\
\text { Intellect }\end{array}$ & $\begin{array}{c}\text { Don't Know } \\
\text { or Don't } \\
\text { Remember }\end{array}$ \\
\hline $\begin{array}{l}\text { Which of these database advertisements did } \\
\text { you notice? }\end{array}$ & & & & \\
\hline $\begin{array}{l}\text { Which of these database advertisements did } \\
\text { you click? }\end{array}$ & & & & \\
\hline $\begin{array}{l}\text { Which of these databases are relevant to } \\
\text { your interests? }\end{array}$ & & & & \\
\hline $\begin{array}{l}\text { Which of these databases have you used } \\
\text { prior to receiving the email advertisements? }\end{array}$ & & & & \\
\hline $\begin{array}{l}\text { Which of these databases are you likely to } \\
\text { use in the future? }\end{array}$ & & & & \\
\hline
\end{tabular}

3. What comments do you have about embedding advertisements in study room reservation emails to make students aware of library resources?

If you would like to enter the draw for $\$ 10$ cash click the "Enter Draw for $\$ 10$ " link. Otherwise, click the "Submit" link.

[Enter Draw for \$10]

[Submit]

Optional Part 2 of Survey

Please provide an email address and your BYU Net ID if you would like to be entered in a draw for one of twenty $\$ 10$ cash awards.

[Submit]

Table 1. Overall survey response by major.

\begin{tabular}{lcc}
\hline Major & Received a survey & Responded \\
\hline Accounting & 305 & 88 \\
Communications & 265 & 75 \\
Management & 246 & 60 \\
Total & $\mathbf{8 1 6}$ & $\mathbf{2 2 3}$ \\
\hline
\end{tabular}


Table 2. Overall advertisement response by major.

\begin{tabular}{lcc}
\hline Major & Saw the ad & Clicked the ad \\
\hline Accounting & 5 & 2 \\
Communications & 5 & 0 \\
Management & 2 & 0 \\
Total & $\mathbf{1 2}$ & $\mathbf{2}$ \\
\hline
\end{tabular}

Table 3. Database relevancy response.

Accounting databases

\begin{tabular}{lccc}
\hline Database & Relevant & Prior use & Future use \\
\hline Tax Notes & 25 & 1 & 18 \\
Accounting \& Tax (ProQuest) & 56 & 18 & 48 \\
RIA Checkpoint Tax Services & 24 & 11 & 22 \\
Total & $\mathbf{1 0 5}$ & $\mathbf{3 0}$ & $\mathbf{8 8}$ \\
\hline
\end{tabular}

Communications databases

\begin{tabular}{lccc}
\hline Database & Relevant & Prior use & Future use \\
\hline Red Books & 4 & 5 & 7 \\
eMarketer & 6 & 5 & 8 \\
Ad Age & 14 & 13 & 17 \\
Total & $\mathbf{2 4}$ & $\mathbf{2 3}$ & $\mathbf{3 2}$ \\
\hline
\end{tabular}

Management databases

\begin{tabular}{lccc}
\hline Database & Relevant & Prior use & Future use \\
\hline IBIS World & 8 & 3 & 7 \\
Euromonitor Passport & 1 & 0 & 3 \\
Mergent Intellect & 2 & 1 & 4 \\
Total & $\mathbf{1 1}$ & $\mathbf{4}$ & $\mathbf{1 4}$ \\
\hline
\end{tabular}


Table 4. Coded comments.

\begin{tabular}{llc}
\hline Code & Description & Count \\
\hline Ignored & $\begin{array}{l}\text { Respondents stated that they do not open study room reservation } \\
\text { confirmation emails. }\end{array}$ & 49 \\
Positive & $\begin{array}{l}\text { Respondents indicated that attaching advertisements to the } \\
\text { reservation emails was a good idea. They expressed interest in } \\
\text { Negative }\end{array}$ & 36 \\
& $\begin{array}{l}\text { Rearning about relevant services. } \\
\text { the reservation emails. They said that doing so would be ineffective or } \\
\text { annoying. }\end{array}$ & \\
Change & $\begin{array}{l}\text { Respondents offered suggestions on how to improve the effectiveness } \\
\text { of the email advertisements. Recommendations included ways to } \\
\text { make the advertisements stand out, such as placing the } \\
\text { advertisements at the top of emails. }\end{array}$ & 37 \\
& & \\
\end{tabular}

